\title{
Controlling Nitrogen Dose Amount in Atmospheric-Pressure Plasma Jet Nitriding
}

\author{
Ryuta Ichiki ${ }^{1, *}$, Masayuki Kono ${ }^{1}$, Yuka Kanbara ${ }^{1}$, Takeru Okada ${ }^{2} \oplus$, Tatsuro Onomoto ${ }^{3}$, \\ Kosuke Tachibana ${ }^{1}$, Takashi Furuki ${ }^{1}$ and Seiji Kanazawa ${ }^{1}$ \\ 1 Division of Electrical and Electronic Engineering, Oita University, Oita 870-1192, Japan; \\ v1652026@oita-u.ac.jp (M.K.); v19e2007@oita-u.ac.jp (Y.K.); tachibana-kosuke@oita-u.ac.jp (K.T.); \\ furuki-takashi@oita-u.ac.jp (T.F.); skana@oita-u.ac.jp (S.K.) \\ 2 Department of Electronic Engineering, Tohoku University, Sendai 980-8579, Japan; \\ takeru.okada@tohoku.ac.jp \\ 3 Material Technology Division, Fukuoka Industrial Technology Center, Kitakyushu 807-0831, Japan; \\ onomoto@fitc.pref.fukuoka.jp \\ * Correspondence: ryu-ichiki@oita-u.ac.jp; Tel.: +81-97-554-7826
}

Received: 25 April 2019; Accepted: 24 June 2019; Published: 25 June 2019

\begin{abstract}
A unique nitriding technique with the use of an atmospheric-pressure pulsed-arc plasma jet has been developed to offer a non-vacuum, easy-to-operate process of nitrogen doping to metal surfaces. This technique, however, suffered from a problem of excess nitrogen supply due to the high pressure results in undesirable formation of voids and iron nitrides in the treated metal surface. To overcome this problem, we have first established a method to control the nitrogen dose amount supplied to the steel surface in the relevant nitriding technique. When the hydrogen fraction in the operating gas of nitrogen/hydrogen gas mixture increased from $1 \%$ up to $5 \%$, the nitrogen density of the treated steel surface drastically decreased. As a result, the formation of voids were suppressed successfully. The controllability of the nitrogen dose amount is likely attributable to the density of $\mathrm{NH}$ radicals existing in the plume of the pulsed-arc plasma jet.
\end{abstract}

Keywords: plasma nitriding; atmospheric-pressure plasma; nitrogen dose amount; hydrogen fraction; void

\section{Research Background}

Plasma nitriding is a surface technology to dope nitrogen atoms into metal surfaces via plasma chemical reactions to improve wear resistance, and fatigue strength, etc., of materials [1-16]. Plasma nitriding is now one of the essential surface treatments used in industry, especially in the automobile industry and die/mold fabrication. Conventional plasma nitriding uses low-pressure DC (or pulsed DC) plasmas in the abnormal glow discharge mode, where the batch process with a large vacuum furnace meets the purpose of mass production. In addition, a number of low-pressure plasma modes have recently been applied to nitriding treatment, e.g., active screen plasmas [4-6], electron cyclotron resonance plasmas [2,7], and radio-frequency plasmas [8], etc.

As another technological seed, nitriding methods using atmospheric-pressure plasmas have been developed, where the disuse of vacuum equipment makes the process much quicker and easier-to-operate. Two types of atmospheric-pressure plasmas are utilized to nitriding, namely the pulsed-arc (PA) plasma jet [17-22] and the dielectric barrier discharge (DBD) [23,24]. The PA plasma-jet nitriding has proved to be available to die steel $[17,18,22]$, austenitic stainless steel [20], and titanium alloy $[19,21]$, where the jet plume is sprayed onto the sample surface to thermally diffuse nitrogen atoms into it. Note that the nitrogen/hydrogen gas mixture is used as the operating gas. The plasma-jet 
nitriding will offer a drastically economical method to us compared with conventional plasma nitriding, especially when high-mix low-volume production is targeted.

The plasma-jet nitriding, however, is a relatively new, still developing technology. Thus, its controllability and reliability has to be improved further for practical application. For example, we had no methods to control the nitrogen dose amount from the jet plume to the metal surface, while such a method has been completed for conventional nitriding in which the nitrogen dose is well-controlled by adjusting the nitriding potential [25]. Due to the lack of dose controllability, the plasma-jet nitriding suffers from a problem of excess nitrogen supply due to the high pressure results in undesirable formation of voids and iron nitrides (the compound layer) attributed to nitrogen gas precipitation in the treated metal surface.

In this paper, a newly developed method is detailed to control nitrogen dose amount in plasma-jet nitriding to overcome the problem of excess nitrogen supply. A brief introduction of the method is as follows. The operating gas to generate the plasma jet is a nitrogen/hydrogen gas mixture. The optical emission spectroscopy proved that $\mathrm{NH}$ radical emission is dominant from the jet plume. In general, the $\mathrm{NH}$ emission intensity tends to decrease with increasing hydrogen fraction in the operating gas, $f_{\mathrm{H} 2}$. If $\mathrm{NH}$ is the key radical for plasma-jet nitriding and if the decreasing tendency of $\mathrm{NH}$ emission with $f_{\mathrm{H} 2}$ indicates decreasing $\mathrm{NH}$ density in the jet plume, we could decrease the nitrogen dose amount to metal surface by increasing $f_{\mathrm{H} 2}$. Following this assumption, we addressed to control the nitrogen dose amount by changing $f_{\mathrm{H} 2}$ in this study.

Prior to explaining our research, let us summarize here key species in various plasma nitriding techniques. As for low-pressure plasma nitriding methods, a comprehensive and systematic understanding of key species is not present. For example, several papers suggest the importance of ion species such as $\mathrm{N}^{2+}$ [2], $\mathrm{N}^{+}$[9], and $\mathrm{NH}_{x}{ }^{+}$[10]. On the other hand, Matsumoto et al. proposed that neutral species govern the rate-limiting step [11]. For the radical nitriding, one of the low-pressure plasma nitriding methods using $\mathrm{NH}_{3}$ and $\mathrm{H}_{2}$ gas, $\mathrm{NH}$ radicals are considered to play a key role [12,13]. Besides, some other papers mention the importance of $\mathrm{NH}$ radicals for plasma nitriding $[8,14]$. Moreover, in gas nitriding, $\mathrm{NH}_{3}$ dissociates on an iron surface to $\mathrm{NH}_{2}, \mathrm{NH}_{2}$ dissociates to $\mathrm{NH}$, and $\mathrm{NH}$ dissociates to $\mathrm{N}$ and $\mathrm{H}$, in order, indicating that the presence of $\mathrm{NH}$ is essential for gas nitriding [25]. As described above, a number of studies regard $\mathrm{NH}$ radicals as species effective to nitriding. Thus, our expectation that $\mathrm{NH}$ is key for plasma-jet nitriding is not peculiar.

\section{Experimental Procedure}

Experiments were performed with the PA plasma jet system shown in Figure 1a. The jet nozzle was composed of coaxial cylindrical electrodes. The grounded external electrode measured $35 \mathrm{~mm}$ in inner diameter. The discharge gap was approximately $20 \mathrm{~mm}$. The nitrogen/hydrogen gas mixture was introduced into the nozzle at the total flow rate of $20 \mathrm{slm}$, where the hydrogen fraction, and the ratio of hydrogen flow rate to total flow rate, was $f_{\mathrm{H} 2}$. The low-frequency voltage pulse $(5 \mathrm{kV}$ in height and $21 \mathrm{kHz}$ in repetition) was applied to the inner electrode, resulting in the maximum of the discharge current of ca. 1.2 A. The afterglow of the generated PA plasma was spewed out from the orifice and was $4 \mathrm{~mm}$ in diameter, forming the jet plume containing $\mathrm{NH}$ radicals. 


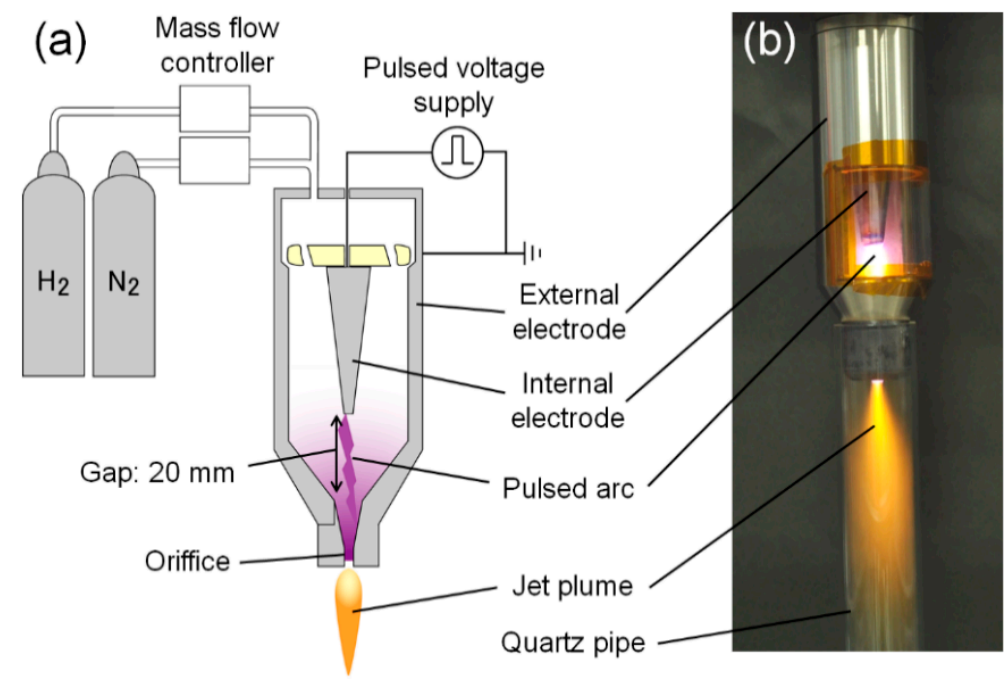

Figure 1. Pulsed-arc plasma jet. (a) Schematic of jet nozzle. (b) Photograph of plasma jet.

For the spectroscopic experiment, the jet nozzle was fitted with a quartz pipe (30 $\mathrm{mm}$ in diameter and $500 \mathrm{~mm}$ in length) at the tip as shown in Figure $1 \mathrm{~b}$ to observe the jet plume generating in the operating gas. The optical emission of $\mathrm{NH}\left(\mathrm{A}^{3} \Pi-\chi^{3} \Sigma^{-}\right)$of $336 \mathrm{~nm}$ was detected with a spectrometer (Shamrock SR-500i, Andor, Belfast, UK). We collected the light emitted from the jet plume at the distance of $10 \mathrm{~mm}$ from the nozzle tip.

For the nitriding experiment, the jet nozzle was inserted into a cylindrically shaped cover made of quartz as shown in Figure 2 to purge residual oxygen from the treatment atmosphere. The height and diameter of the quartz cover was 85 and $124 \mathrm{~mm}$, respectively. The gas was exhausted through the 1-mm gap between the jet nozzle and the quartz cover. The experimental system was put in a simple booth $\left(1.0 \times 1.2 \times 1.8\right.$ (height) $\left.\mathrm{m}^{3}\right)$ surrounded by a vinyl curtain to lead the exhaust gas to the gas-treatment equipment. Prior to generating the plasma jet, residual oxygen inside the cover was gas-purged by the operating gas introduced through the nozzle.

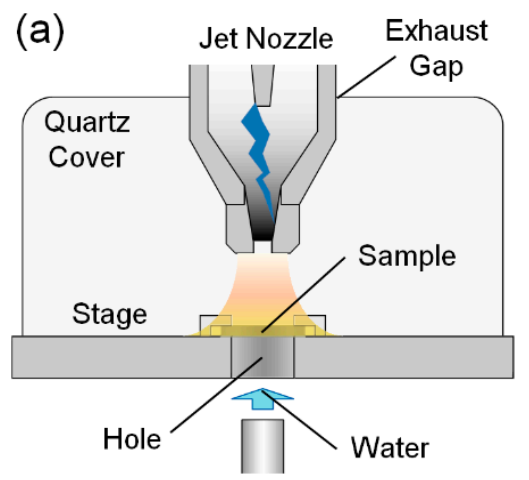

(b)

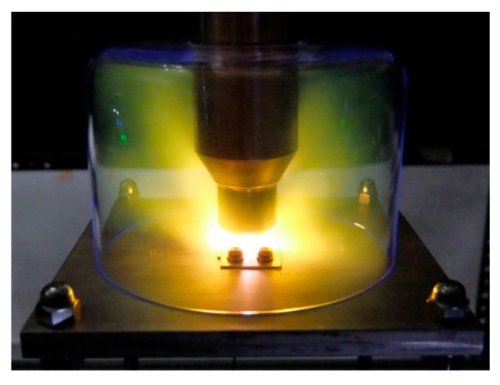

Figure 2. Experimental Setup with the quartz cover to purge residual oxygen. (a) Schematic. (b) Photograph of plasma-jet nitriding.

The steel to be treated was cold roll steel JIS SPCC. The composition was as follows: $0.02 \% \mathrm{C}$, $0.09 \% \mathrm{Mn}, 0.017 \% \mathrm{P}, 0.004 \% \mathrm{~S}$, and the balance was Fe. The sample dimension was $25 \times 25 \times 1.2 \mathrm{~mm}^{3}$. The hardness of base material was ca. $150 \mathrm{HV}$. The surface was mirror finished with alumina powder $(1 \mu \mathrm{m})$ and degreased in an ultrasonic acetone bath.

To make the effects of nitrogen dose amount as conspicuous as possible, the surface temperature was set into the range of 1000 to $1100 \mathrm{~K}$ during nitrogen doping and the doped sample was immediately quenched to invoke iron-nitrogen martensite transformation. Such nitro-quenching treatment was 
known to form voids, which can be readily observed with a microscope, in the surface when excess nitrogen was doped [26]. In addition, the formation of iron-nitrogen martensite indicated to us the answer as to whether or not a non-trivial amount of nitrogen had been doped even when the nitrogen dose amount was intently reduced to suppress the formation of voids. The surface temperature of ca. 1000-1100 K was maintained by the plasma-jet spraying itself, where the distance between the nozzle tip to the surface was set to $7 \mathrm{~mm}$. The treatment temperature was measured by spraying the jet plume to a dummy sample with a thermocouple on the surface. The doping duration was 900 to $1800 \mathrm{~s}$. The doped steel was quenched by water cooling, where tap water was poured onto the opposite surface through the hole bored in the center of the sample stage.

The doped nitrogen concentration in the steel surface was detected by an electron probe micro analyzer (EPMA, JXA-8200SP, JEOL, Tokyo, Japan). The void formation and the metallographic structure were observed with an optical microscope (VHX-5000, KEYENCE, Osaka, Japan) to a cross-section of doped steel surface. The sample surface was etched in nital solution (3\%) for observing the metallographic structure. The formation of iron nitrides was detected by X-ray diffraction (XRD, SmartLab, Rigaku, Tokyo, Japan) using Co K $\alpha$ radiation $(\lambda=0.179 \mathrm{~nm})$. The hardness profile of the cross-section was measured with a Vickers microhardness tester (FM-300, FUTURE-TECH, Kawasaki, Japan), where the indenter load was $0.098 \mathrm{~N}$ and the loading time was $10 \mathrm{~s}$.

\section{Results and Discussions}

\subsection{NH Emission Intensity}

Figure 3 shows the $f_{\mathrm{H} 2}$ dependence of the emission intensity of $\mathrm{NH}$ radicals from the jet plume. The NH emission intensity increased with increasing $f_{\mathrm{H} 2}$ up to $0.25 \%$. On the contrary, the NH emission intensity turned to decrease with increasing $f_{\mathrm{H} 2}$ over $0.25 \%$ up to $5 \%$. The decreasing tendency of the emission intensity suggested the likely possibility that the density of $\mathrm{NH}$ radical existing in the jet plume decreased with increasing $f_{\mathrm{H} 2}$ in the range more than $0.25 \%$. Following this suggestion, we increased $f_{\mathrm{H} 2}$ for the purpose of decreasing the nitrogen dose amount. Incidentally, the minimum $f_{\mathrm{H} 2}$ was set to $1 \%$ in this study because by our previous work, $f_{\mathrm{H} 2}$ was less than $1 \%$ proved to result in oxidization of the steel surface due to the lack of reduction performance against residual oxygen [18].

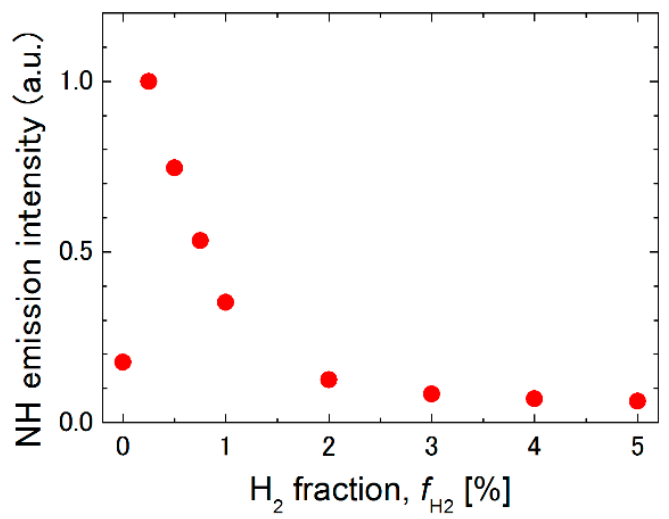

Figure 3. Emission intensity of $\mathrm{NH}$ radicals $(336 \mathrm{~nm})$ in jet plume $\mathrm{vs}_{2}$ fraction in the operating gas.

\subsection{Nitrogen Density of Treated Steel Surface}

Figure $4 \mathrm{a}, \mathrm{b}$ shows the cross-sectional mapping and depth profile of nitrogen concentration, respectively, where the observation point was at the center of plasma-jet spraying. For $f_{\mathrm{H} 2}$ of $1 \%$, nitrogen was considerably condensed in the surface. In the vicinity of the outermost surface, the nitrogen concentration reached ca. 12 at $\%$ and monotonically decreased in the depth direction. The concentration gradient was a typical characteristic in such a diffusion treatment. On the other hand, the nitrogen concentration in the vicinity of the surface became obviously less for $f_{\mathrm{H} 2}$ of $2.5 \%$ 
even though the gradient tendency was analogous. The maximum concentration was merely 4 at $\%$ in this case. Moreover, further decreases in nitrogen concentration was seen for $f_{\mathrm{H} 2}$ of $5 \%$, where the maximum value was reduced down to 2 at $\%$. In summary, the nitrogen concentration in the doped steel surface monotonically decreased with increasing $f_{\mathrm{H} 2}$, while it maintained the gradient tendency in the depth direction. This result indicates that the nitrogen dose amount was successfully controlled by changing $f_{\mathrm{H} 2}$.

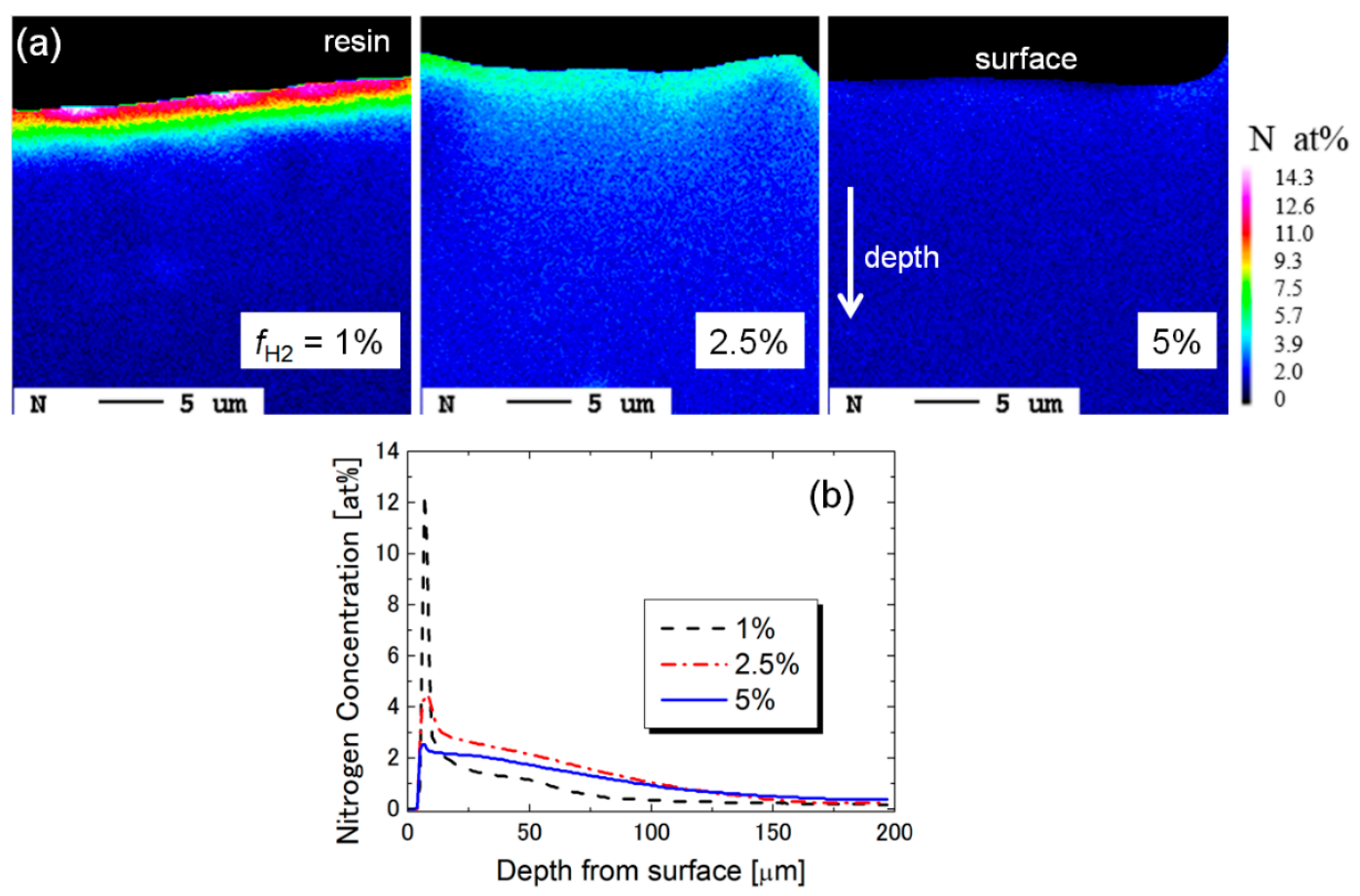

Figure 4. Distribution of nitrogen concentration for several $f_{\mathrm{H} 2}$. The doping duration was $1800 \mathrm{~s}$. (a) Two-dimensional mapping of sample cross-section in the vicinity of treated surface. (b) One-dimensional depth profile.

\subsection{Formation of Voids}

Figure 5 shows cross-sectional micrographs of doped steels observed in the vicinity of the center of plasma-jet spraying. For $f_{\mathrm{H} 2}$ of $1 \%$, a number of black dots were seen, which corresponded to the voids due to excess nitrogen doping. The existence of such voids would have made the material surface extremely brittle. On the other hand, the number of voids tended to decrease with increasing $f_{\mathrm{H} 2}$ and as a consequence, they become invisible in the optical microscopic scale for $f_{\mathrm{H} 2}$ of $5 \%$. This result indicates that increasing $f_{\mathrm{H} 2}$ can suppress the void formation in the steel surface. From the tendency of nitrogen concentration described in Section 3.2, it follows that decreasing the nitrogen dose amount was the cause of the suppression of void formation. 


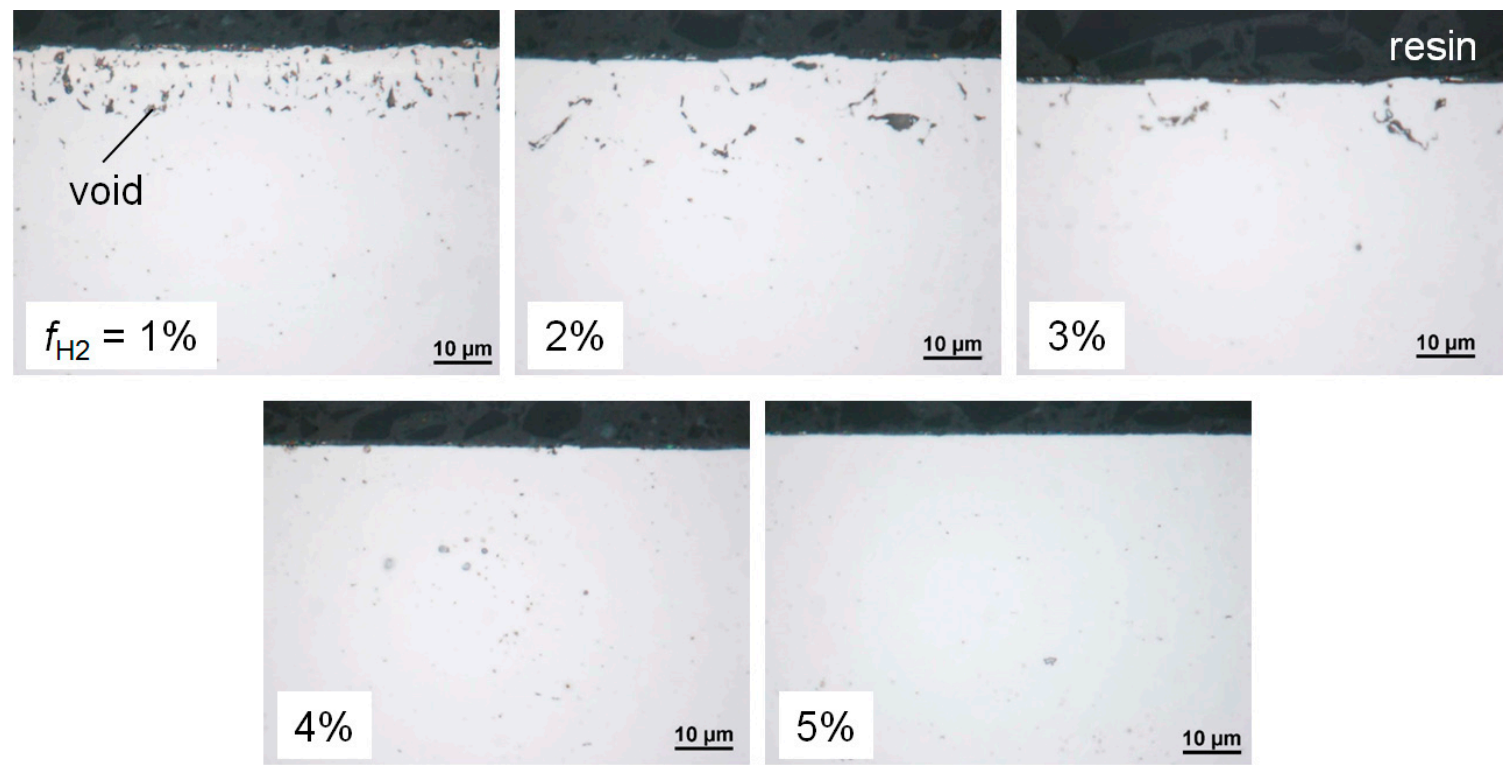

Figure 5. Micrographs of sample cross-section. The dots appearing in the vicinity of surface correspond to voids. The doping duration was $900 \mathrm{~s}$.

\subsection{Formation of Compound Layer}

Figure 6 shows XRD spectra of the treated steel surface, where the observation point was the sample surface in the vicinity of the center of plasma-jet spraying. For $f_{\mathrm{H} 2}$ of $1 \%$, the treated surface obviously contained iron nitrides, namely $\mathrm{Fe}_{4} \mathrm{~N}$ ( $\gamma^{\prime}$ phase) and $\mathrm{Fe}_{2-3} \mathrm{~N}(\varepsilon$ phase). On the other hand, the spectral intensities of the iron nitrides suddenly decreased with increasing $f_{\mathrm{H} 2}$ and as a consequence, they became less than the detection limit for $f_{\mathrm{H} 2}$ over $2 \%$. This result indicated that increasing $f_{\mathrm{H} 2}$ reduced the formation of iron nitrides in the steel surface. From the tendency of nitrogen concentration described in Section 3.2, it follows that the formation of iron nitrides was suppressed owing to a decreasing nitrogen dose amount.

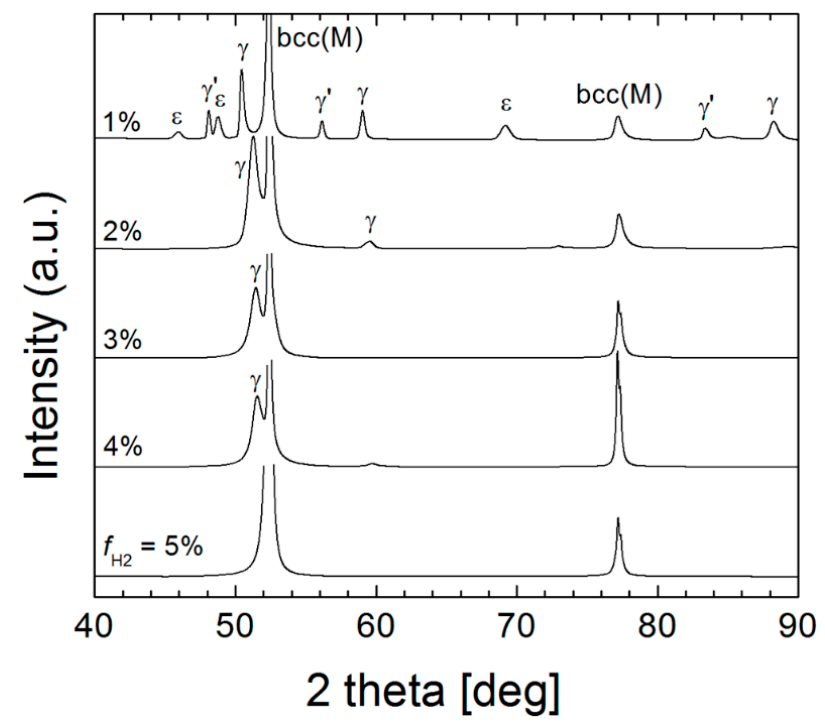

Figure 6. XRD spectra of treated steel surface in the vicinity of the center of plasma-jet spraying.

In addition, the XRD peaks of the retained austenite ( $\gamma$ phase) were clearly seen. The formation of the retained austenite was attributed to the austenitic transformation over the critical temperature $A_{1}$ and an excess solution of nitrogen. The formation of retained austenite can be regarded as another 
negative effect of excess nitrogen supply as well as the voids and iron nitrides. However, Figure 6 exhibits that the peak intensity of $\gamma$ tended to decrease with increasing $f_{\mathrm{H} 2}$, indicating that the amount of retained austenite was reduced. Moreover, the $\gamma$ peak shifts toward high theta with $f_{\mathrm{H} 2}$, that resulted from decreasing the lattice constant due to decreasing dissolved nitrogen concentration. From the relationship between the austenitic lattice constant $a$ and the dissolved nitrogen concentration $X_{\mathrm{N}}$ in atomic percentage $\left(a / \mathrm{nm}=0.3564+0.00077 X_{\mathrm{N}}\right)$ [26], we obtained the dependence of $X_{\mathrm{N}}$ on $f_{\mathrm{H} 2}$ as shown in Figure 7. For $f_{\mathrm{H} 2}=1 \%, X_{\mathrm{N}}=9.6$ at $\%$. Increasing $f_{\mathrm{H} 2}$ monotonically decreased $X_{\mathrm{N}}$ and for $f_{\mathrm{H} 2}=4 \%, X_{\mathrm{N}}$ was reduced down to 0.26 at $\%$. These characteristics of retained austenite are additional evidence for the controllability of nitrogen dose amount.

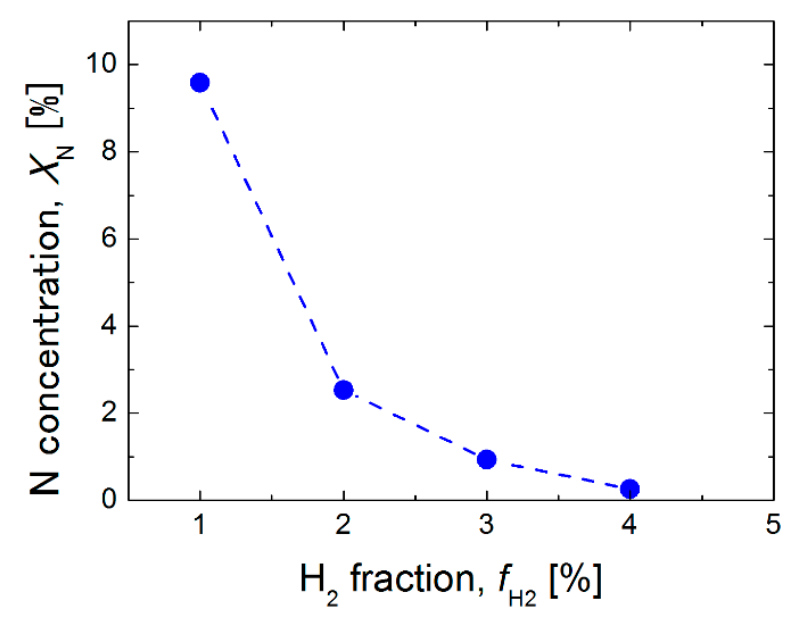

Figure 7. Nitrogen concentration in retained austenite calculated from the XRD spectral shift.

\subsection{Hardness Profile}

Figure 8 shows the two-dimensional hardness profiles of the cross-section of treated steels. The horizontal axis is the surface position of sample, the origin of which corresponds to the center of plasma-jet spraying. The vertical axis is the depth from surface. Here the micro-Vickers hardness was measured at intervals of $2 \mathrm{~mm}$ in the horizontal direction and $10 \mu \mathrm{m}$ in the vertical direction. The hardness is displayed by gray scale. 

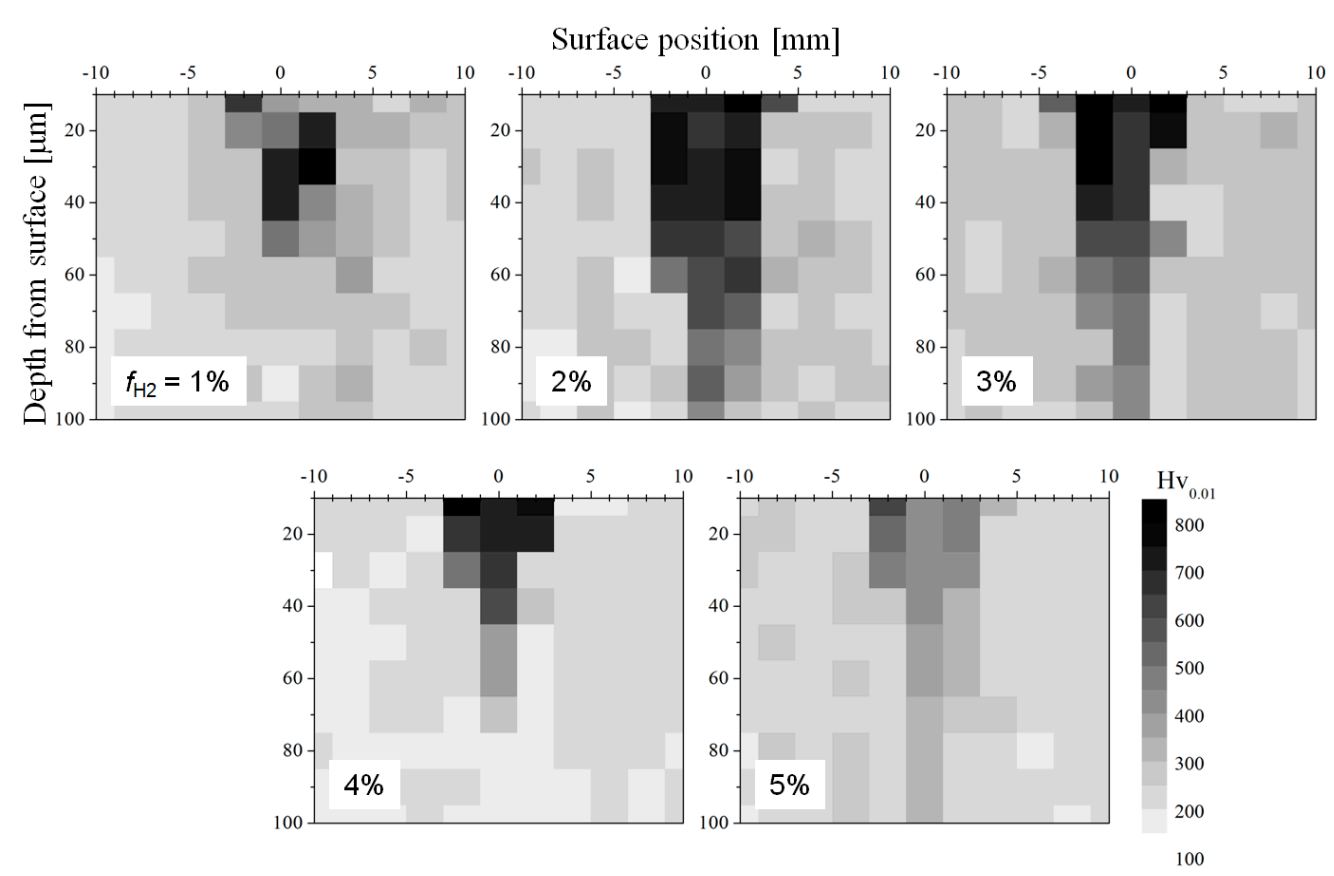

Figure 8. Two-dimensional hardness profiles of sample cross-section. The micro-Vickers hardness is displayed by gray scale. The doping duration was $900 \mathrm{~s}$.

We see that for every $f_{\mathrm{H} 2}$, the hardness beneath the center of plasma-jet spraying was increased significantly beyond the original hardness. Here the area of ca. $5 \mathrm{~mm}$ in diameter was locally hardened. The local hardening was most likely due to the limited heating ability of the plasma jet only to a narrow area, not due to local nitrogen supply because of the following fact. It has already been proved that nitrogen can be supplied to the circular area as large as $20 \mathrm{~mm}$ in diameter by identical plasma-jet spraying, where the steel sample was heated up to ca. $800 \mathrm{~K}$ with the assistance of an external heater [18]. The highest hardness was $815,755,815,822$, and $606 \mathrm{HV}$ for $f_{\mathrm{H} 2}=1 \%, 2 \%, 3 \%$, $4 \%$, and $5 \%$, respectively. Such hardness cannot be obtained without nitrogen doping because the original carbon content was too low in the sample to invoke iron-carbon martensite transformation. Although the hardness was relatively low when $f_{\mathrm{H} 2}=5 \%$, the drastic increase in hardness proved that the nitrogen dose amount was still appropriate.

Figure 9 shows the depth profile of hardness averaged within the range of $\pm 2.5 \mathrm{~mm}$ of the surface position. The error bar corresponds to the standard deviation of each of the three data sets. We can see the typical trend of hardness gradient for every $f_{\mathrm{H} 2}$. Note that for $f_{\mathrm{H} 2}=1 \%$, obvious softening occurs in the outermost surface within the depth profile from 10 to $30 \mu \mathrm{m}$. (This is clearly seen also in Figure 8.) This softening was possibly due to the considerable amount of retained austenite. For $f_{\mathrm{H} 2}=2 \%$, the softening effect became much weaker and for more $f_{\mathrm{H} 2}$ it was not seen any more. The dependence of the softening effect on $f_{\mathrm{H} 2}$ is consistent with the peak intensity of $\gamma$ shown in Figure 6 . The outermost hardness of $f_{\mathrm{H} 2}=3 \%$ and $4 \%$ reached the largest value of ca. $800 \mathrm{HV}$. For $f_{\mathrm{H} 2}=5 \%$ it became lesser, likely due to a lower nitrogen dose amount. 


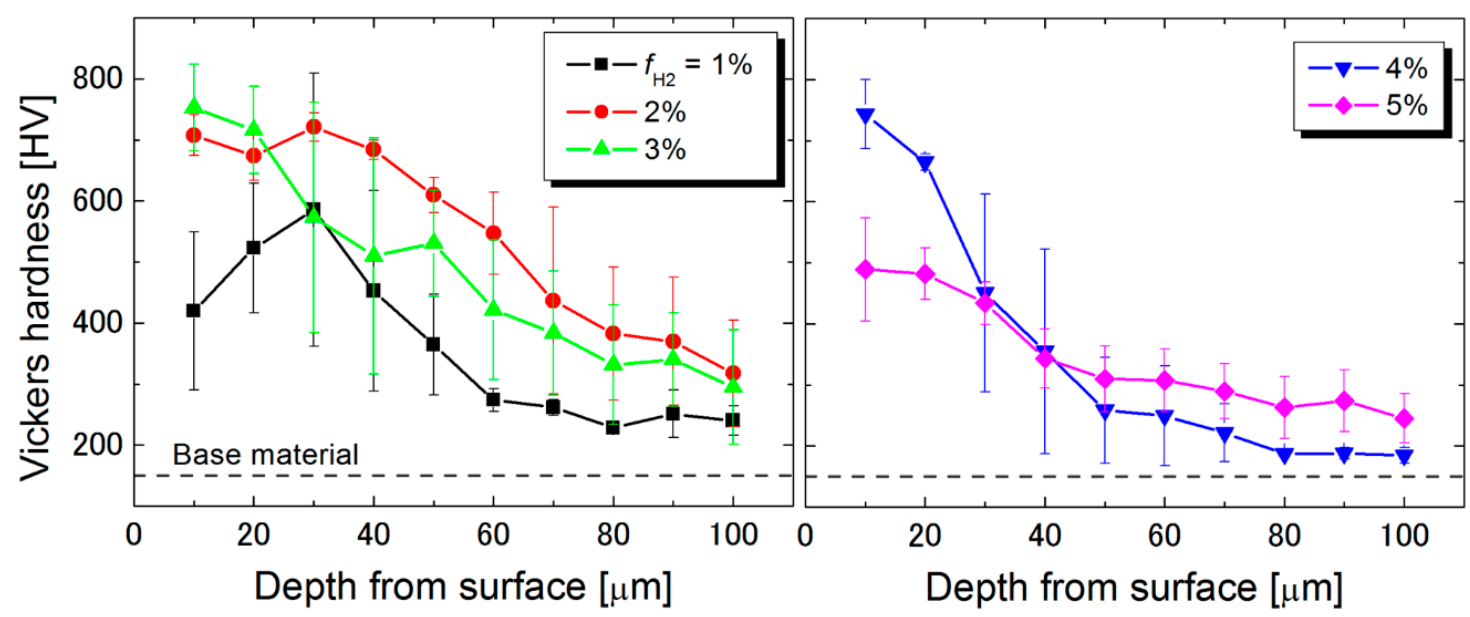

Figure 9. Depth profile of hardness of sample cross-section. The error bars correspond to the standard deviation.

\subsection{Metallographic Structure}

Figure 10 shows the metallographic micrographs of sample cross-section in the vicinity of the surface. Here the martensite layer and the compound layer are denoted by $\mathrm{m}$ and c, respectively. For $f_{\mathrm{H} 2}=1 \%$, the compound layer was clearly seen as a discontinuous thin layer. However, no discontinuous layer appeared for more $f_{\mathrm{H} 2}$, being consistent with the behavior of $\gamma^{\prime}$ and $\varepsilon$ peaks shown in Figure 6.
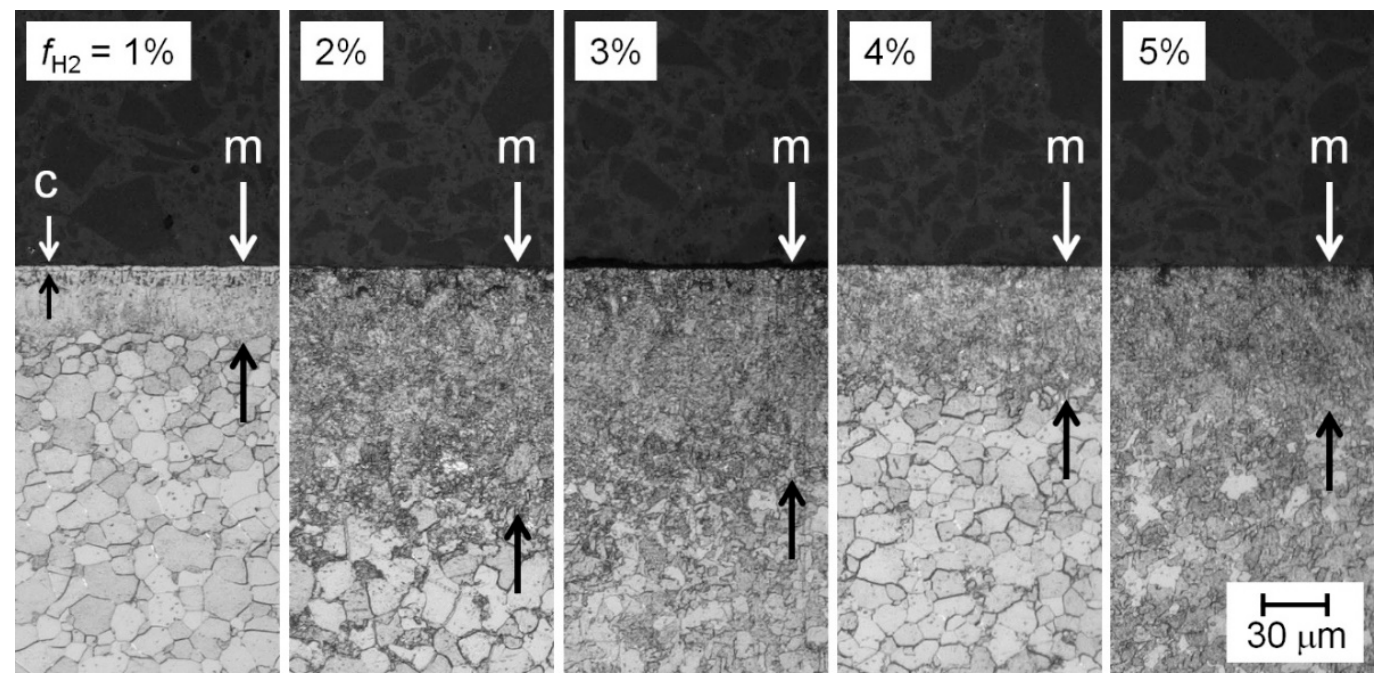

Figure 10. Metallographic micrograph of sample cross-section. The arrow pairs denoted by $\mathrm{m}$ and $\mathrm{c}$ specify the vertical range of the martensite layer and the compound layer, respectively.

The thickness of the martensite layer depended on $f_{\mathrm{H} 2}$. That is, the thickness increased with increasing $f_{\mathrm{H} 2}$ up to $2 \%$, and turned to a decrease from $2 \%$ to $4 \%$, and then kept constant for more $f_{\mathrm{H} 2}$. We consider that the thickness change was caused by a shift of the surface temperature. The temperature of jet plume tended to increase with increasing $f_{\mathrm{H} 2}$ owing to the high thermal conductivity of hydrogen, transporting the thermal energy from the pulsed arc to the jet plume. The sample temperature (measured with a dummy sample) was ca. $1000 \mathrm{~K}$ for $f_{\mathrm{H} 2}=1 \%$ but increased up to ca. $1100 \mathrm{~K}$ for more $f_{\mathrm{H} 2}$. From this fact, it follows that the increase in the thickness from $f_{\mathrm{H} 2}=1 \%$ to $2 \%$ was caused by the enhanced thermal diffusion and the subsequent decrease was caused by the decrease in nitrogen dose amount. The change in the layer thickness can be seen also in Figures 8 and 9. 


\section{Conclusions}

To overcome the problem of excess nitrogen supply in the PA plasma-jet nitriding, a controlling method of nitrogen dose amount was proposed on the basis of $\mathrm{NH}$ radical emission and was addressed to experimentally performed. Consequently, we have demonstrated that the nitrogen dose amount to the steel surface can be controlled by changing the hydrogen fraction in the operating gas. As a result of nitrogen dose control, undesirable formation of voids and iron nitrides were successfully suppressed, while a nitrogen dose enough to invoke martensite transformation was simultaneously achieved.

This achievement means that we have first obtained the technique to control "the nitriding potential" even in the new plasma-jet nitriding. We believe that the upgraded controllability presented here was of great help for future practical applications of the plasma-jet nitriding, especially for applications to high-mix low-volume production of mechanical and medical fabrications. Note that although the treatable area in this study seems too small for practical use, we can practically treat the circular area of at least $20 \mathrm{~mm}$ in diameter for the ordinary nitriding temperature at ca. $800 \mathrm{~K} \mathrm{[18].}$

Author Contributions: Conceptualization, all; data curation, R.I., M.K. and Y.K., methodology, R.I., M.K. and Y.K.; investigation, R.I., M.K., Y.K., T.O. (Takeru Okada), T.O. (Tatsuro Onomoto), K.T., T.F. and S.K.; writing一original draft preparation, R.I.; writing-review and editing, K.T. and S.K.; visualization, M.K., Y.K., T.O. (Takeru Okada), T.O. (Tatsuro Onomoto) and T.F.; supervision, R.I.; project administration, R.I.; funding acquisition, R.I.

Funding: This work was supported by JSPS KAKENHI Grant Number 15K17482.

Acknowledgments: We wish to acknowledge valuable discussions with Masahiro Okumiya, Toyota Technological Institute, and Nobuyuki Kanayama, Santier Giken Co., Ltd. We are grateful to Masaki Sonoda, Oita Industrial Research Institute, for their technical assistance.

Conflicts of Interest: The authors declare no conflicts of interest.

\section{References}

1. Sun, Y.; Bell, T. Plasma surface engineering of low alloy steel. Mater. Sci. Eng. 1991, 140, 419-434. [CrossRef]

2. Czerwiec, T.; Michel, H.; Bergmann, E. Low-pressure, high-density plasma nitriding: Mechanisms, technology and results. Surf. Coat. Technol. 1998, 108-109, 182-190. [CrossRef]

3. Rie, K.-T. Recent advances in plasma diffusion processes. Surf. Coat. Technol. 1999, 112, 56-62. [CrossRef]

4. Li, C.X. Active screen plasma nitriding-An overview. Surf. Eng. 2010, 26, 135-141. [CrossRef]

5. Nishimoto, A.; Tanaka, T.; Matsukawa, T. Effect of surface deposited layer on active screen plasma nitriding. Mater. Perform. Charact. 2016, 5, 386-395. [CrossRef]

6. Nishimoto, A.; Matsukawa, T.; Nii, H. Effect of screen open area on active screen plasma nitriding of austenitic stainless steel. ISIJ Int. 2014, 54, 916-919. [CrossRef]

7. Marcos, G.; Guilet, S.; Cleymand, F.; Thiriet, T.; Czerwiec, T. Stainless steel patterning by combination of micro-patterning and driven strain produced by plasma assisted nitriding. Surf. Coat. Technol. 2011, 205, S275-S279. [CrossRef]

8. Aizawa, T.; Morita, H.; Wasa, K. Low-temperature plasma nitriding of Mini-/Micro-tools and parts by table-top system. Appl. Sci. 2019, 9, 1667. [CrossRef]

9. Michel, H.; Czerwiec, T.; Gantois, M.; Ablitzer, D. Progress in the analysis of the mechanisms of ion nitriding. Surf. Coat. Technol. 1995, 72, 103-111. [CrossRef]

10. Hudis, M. Study of ion-nitriding. J. Appl. Phys. 1973, 44, 1489. [CrossRef]

11. Matsumoto, O.; Konuma, M.; Kanzaki, Y. Nitriding of titanium in an r.f. discharge II: Effect of the addition of hydrogen to nitrogen on nitriding. J. Less Common Met. 1982, 84, 157-163. [CrossRef]

12. Sakamoto, Y.; Takaya, M.; Ishii, Y.; Igarashi, S. Surface modified tool fabricated by radical nitriding. Surf. Coat. Technol. 2001, 152-155. [CrossRef]

13. Lee, I.; Park, I. Microstructure and mechanical properties of surface-hardened layer produced on SKD 61 steel by plasma radical nitriding. Mater. Sci. Eng. 2007, 449, 890-893. [CrossRef]

14. Tamaki, M.; Tomii, Y.; Yamamoto, N. The role of hydrogen in plasma nitriding: Hydrogen behavior in the titanium nitride layer. Plasmas Ions 2000, 3, 33-39. [CrossRef]

15. Tahchieva, A.B.; Llorca-Isern, N.; Cabrera, J.-M. Duplex and superduplex stainless steels: microstructure and property evolution by surface modification processes. Metals 2019, 9, 347. [CrossRef] 
16. Almeida, G.F.C.; Couto, A.A.; Reis, D.A.P.; Massi, M.; Da Silva Sobrinho, A.S.; De Lima, N.B. Effect of plasma nitriding on the creep and tensile properties of the Ti-6Al-4V alloy. Metals 2018, 8, 618. [CrossRef]

17. Ichiki, R.; Nagamatsu, H.; Yasumatsu, Y.; Iwao, T.; Akamine, S.; Kanazawa, S. Nitriding of steel surface by spraying pulsed-arc plasma jet under atmospheric pressure. Mater. Lett. 2012, 71, 134-136. [CrossRef]

18. Nagamatsu, H.; Ichiki, R.; Yasumatsu, Y.; Inoue, T.; Yoshida, M.; Akamine, S.; Kanazawa, S. Steel nitriding by atmospheric-pressure plasma jet using $\mathrm{N}_{2} / \mathrm{H}_{2}$ mixture gas. Surf. Coat. Technol. 2013, 225, 26-33. [CrossRef]

19. Yoshimitsu, Y.; Ichiki, R.; Kasamura, K.; Yoshida, M.; Akamine, S.; Kanazawa, S. Atmospheric-pressure plasma nitriding of titanium alloy. Jpn. J. Appl. Phys. 2015, 54, 030302. [CrossRef]

20. Maeda, A.; Ichiki, R.; Tomizuka, R.; Nishiguchi, H.; Onomoto, T.; Akamine, S.; Kanazawa, S. Investigation on local formation of expanded austenite phase by atmospheric-pressure plasma jet. In Proceedings of the XXXIII International Conference on Phenomena in Ionized Gases, Estoril, Portugal, 9-14 July 2017; Alves, L.L., Tejero-del-Caz, A., Eds.; p. 169.

21. Sannomiya, R.; Ichiki, R.; Otani, R.; Hanada, K.; Sonoda, M.; Akamine, S.; Kanazawa, S. Investigation on hard-tissue compatibility of TiN surface formed by atmospheric pressure plasma nitriding. Plasma Fusion Res. 2018, 13, 1306120. [CrossRef]

22. Chiba, S.; Ichiki, R.; Nakatani, T.; Ueno, T.; Kanazawa, S. Development of local evacuation system for inhibiting oxidization in atmospheric-pressure plasma jet nitriding. Results Phys. 2019, 13, 102131. [CrossRef]

23. Miyamoto, J.; Inoue, T.; Tokuno, K.; Tsutamori, H.; Abraha, P. Surface modification of tool steel by atmospheric-pressure plasma nitriding using dielectric barrier discharge. Tribol. Online 2016, 11, 460-465. [CrossRef]

24. Kitamura, K.; Ichiki, R.; Tsuru, T.; Akamine, S.; Kanazawa, S. Demonstration of nitriding by dielectric barrier discharge and investigation of treatment range controllability. In Proceedings of the 21st International Conference on Gas Discharges and their Applications, Nagoya, Japan, 11-16 September 2016; Yokomizu, Y., Kojima, H., Eds.; pp. 429-432.

25. Liedtke, D. Gas Nitriding and Nitrocarburizing. In Wärmebehandlung von Eisenwerkstoffen II: Nitrieren und Nitrocarburieren; Expert Verlag: Renningen, Germany, 2014.

26. Chiba, M.; Miyamoto, G.; Furuhara, T. Microstructure of pure iron treated by nitriding and quenching process. J. Jpn. Inst. Metals 2012, 76, 256-264. [CrossRef] 